\title{
MEMBACA GENDER DALAM KONTEKS POSTMEMORY
}

\author{
Isti Kumalasari
}

Alumni S2 Ilmu Sastra FIB UGM

\begin{abstract}
Judul Buku The Generation of Postmemory: Writing and Visual Culture after the Holocaust | Pengarang: Marianne Hirsch | Penerbit: Columbia University Press | Tahun: 2012. Halaman: 305
\end{abstract}

$\mathrm{D}^{\mathrm{a}}$ alam bukunya yang berjudul The Generation of Postmemory: Writing and Visual Culture after the Holocaust, Marianne Hirsch mencoba memformulasikan kajian Holocaust dan memori dengan menggunakan perspektif feminis melalui studi komparatif beberapa karya yang ditulis oleh generasi kedua. Pijakan Hirsch mengenai hal ini muncul dari pertanyaan besar tentang absennya wajah perempuan dalam pemutaran film karya Claude Lanzman yang berjudul Shoah di Dartsmouth's Loews Theater pada tahun 1986. Dalam film yang sangat monumental tersebut, proses pengambilan gambar ditekankan pada keseharian para korban di dalam kamp konsentrasi dan difokuskan pada laki-laki saja. Suara perempuan sama sekali tidak ditampilkan dalam layar kecuali hanya beberapa friksi di mana mereka diijinkan untuk bernyanyi tetapi tidak untuk memberikan testimoni akan pengalaman mereka berada di kamp konsentrasi tersebut. Hanya para pria yang diijinkan untuk melakukan interview padahal tujuan politis dari penghancuran kaum Yahudi pada masa itu ditargetkan semua pihak tanpa adanya perbedaan umur ataupun gender. Sehingga pertanyaanpertanyaan lebih lanjut muncul seperti, mengapa wajah perempuan menjadi langka? Dan mengapa perempuan hanya sebagai translator atau mediator dari testimoni peristiwa tersebut?

Hirsch (2012: 5) menjelaskan bahwa

postmemory describes the relationship that the generation after bears to the personal, collective, and cultural trauma of those who came before- to experiences they "remember" only by means of the stories, images, and behaviors among which they grew up. But these experiences were transmitted to them so deeply and affectively as to seem to constitute memories in their own right.

Pendekatan feminis yang digunakan Hirsch dalam bukunya tersebut berusaha untuk mengupas bentuk retorika dan politik dari memori dan transmisi dengan merujuk pada pertanyaan besar yang terlontar pada pembacaan film Shoah. Tentu saja, Hirsch sedikit banyak dipengaruhi oleh beberapa ahli dalam sejarah dan memori seperti Mauriche Halbwachs, Pierre Nora, dan Michel Foucault dan dari segi psikoanalisis dan trauma seperti Sigmund Freud, Melanie Klein, Virginia Wolf, Toni Morisson, Hannah Arendt, Eva Hoffman, Shoshana Felman dan Cathy Caruth. Perbedaan antara postmemory dan memori bagi Hirsch adalah sama seperti halnya Freud membedakan antara realitas fisik dan materi, antara pengalaman yang dikendalikan oleh proses ketidaksadaran dan kesadaran. Yang pertama tidaklah dengan serta merta hadir tetapi mempunyai efek yang sama besarnya (Stuber, 2013). Pandangan Claire Kahane (via Hirsch, 2012: 17) yang mencoba mengulas antara psikoanalisis dan gender yang menyatakan bahwa "if bysteria put gender at the very center of subjectivity, trauma, in its attention to the assault on the ego and the disintegration of the subject, seems to cast gender as irrelevant" seolah menjadi oposisi 


\section{Jurnal Poetika Vol. IV No. 1, Juli 2016}

bagi Hirsch yang mengambil perspektif feminis dalam mengkaji Holocaust dan postmemory. Menanggapi hal tersebut, Hirsch mencoba untuk menunjukkan dua tujuan penting yang ingin ditekankannya dalam melakukan reframing. Di satu sisi, dia ingin menghindari cara yang sering digunakan oleh feminist tradisional yang mencoba untuk menghapus perbedaan gender serta melakukan selebrasi penguatan figur perempuan di atas laki-laki. Di sisi lain, dia ingin berpikir di luar apa yang disebutnya sebagai relevance atau appropriatness sebagai kategori analitis.

Kajian mengenai relasi antara Holocaust dan gender sebenarnya sudah muncul sejak dua dekade lalu namun hingga saat ini akses kita terhadap postmemory Holocaust masih didominasi oleh karya-karya yang bisa dibilang sangat patriarkhi baik yang ditulis oleh generasi pertama seperti Primo Levi ataupun generasi kedua seperti Art Spiegelman, Sebald, dan Christian Boltanski. Jikapun narasi itu ditulis oleh penulis perempuan seperti Anne Michaels dan Lily Brett, garis yang digunakan dalam transmisi penceritaan pun masih berasal dari sudut pandang maskulin yaitu sosok ayah. Titik balik dari kegelisahan Hirsch terjembatani ketika Toni Morisson muncul dengan karyanya Sethe di mana perempuan bertindak sebagai pembawa dan narator dari peristiwa sejarah tersebut.

Oleh karena itu, yang ingin disampaikannya dalam buku tersebut adalah bagaimana gender begitu juga dengan perbedaan seksualitas mampu memberikan beberapa kemungkinan fungsi dalam kajian Holocaust dan memori. Pertama, gender dapat berfungsi sebagai figur yang memediasi cara transmisi dan image tertentu mampu bersirkulasi di antara sistem kultural post-generasi. Seperti yang terjadi dalam menganalisis Maus karya Art Spiegelman dan Austerlitz, karya Sebald, gender begitu berperan dalam hal ini. Absennya figur seorang ibu dalam transmisi yang hanya bisa dilihat melalui foto dan arsip publik menjadikan narasi antara ayah dan anak laki-lakinya bisa berjalan karena dimediasi oleh maternal loss dan maternal recognition. Narasi tersebut bergerak dan begitu hidup di antara keadaan kultural generasi kedua karena hadirnya kerinduan sosok ibu yang hilang karena peristiwa Holocaust. Hal ini bisa terjadi karena karya postmemory merupakan karya yang mengandung emanasi yaitu hasrat dan proyeksi bagi generasi selanjutnya untuk menemukan yang hilang, melengkapi yang terserak, dan atau memperbaiki masa lalu yang traumatis. Sehingga transmisi yang dimediasi oleh hilangnya sosok ibu akan sangat akurat dalam menggerakkan post-generasi dalam memahami dan mencari kebenaran masa lalu tersebut dalam konteks kulturalnya saat ini seperti yang dilakukan oleh Austerlitzyang memahami sosok wanita yang ada dalam film dokumenter sebagai ibunya.

Kedua, dalam beberapa peristiwa sejarah yang bersifat traumatis, gender bisa saja invisible ataupun bypervisible. Hal ini ditunjukkan Hirsch melalui analisisnya tentang representasi umum yang ditunjukkan oleh arsip publik baik di buku atau museum di mana ada kalanya sosok perempuan sama sekali tidak dihadirkan atau kadang justru sangat ditekankan. Bukan hanya sosok perempuan tetapi juga aspek feminitas image yang dipajang dalam museum atau arsip publik. Contoh paling umum yang ditampilkan Hirsch adalah hubungan antara perpetrator dan victim dalam subbab perpetrators' gaze di mana sosok perpetrator akan dibuat sedemikian rupa sehingga ada kesan bypermasculinity sedangkan victim biasanya akan digambarkan dengan sangat berkebalikan dengan membuatnya seolah tidak berdaya atau dalam istilah Hirsch infantilized atau feminized. Kedua jenis representasi ini mengundang dua fungsi yang saling beroposisi, di satu sisi bisa saja membuat trauma begitu tidak tertahankan bagi post-generasi atau justru bertindak sebagai fetish yang melindungi audiens dari efek horor atau trauma berkelanjutan seperti halnya fungsi frame yang menjadi tameng bagi foto-foto yang mengandung memori traumatis.

Ketiga, mengkaji gender dalam postmemory menawarkan bagaimana posisi identitas gender dalam di transmisi baik itu transmisi familial atau afiliatif akan mempunyai dampak dan hasil yang berbeda. Keempat, membaca bagaiamana gender ditampilkan, apakah itu kemudian invisible atau 


\section{Jurnal Poetika Vol. IV No. 1, Juli 2016}

justru hypervisible dalam karya-karya postmemory ataupun arsip publik melalui kacamata feminis tidak hanya dapat mengadirkan pemahaman mengenai narasi mana yang diingat atau dilupakan, atau image mana yang ditampilkan atau disupresi, tetapi juga bagaimana narasinarasi tersebut diceritakan dan bagaimana image tersebut dikonstruksi (Hirsch, 2012: 18).

Melalui pembacaan komparatif dari beberapa karya generasi kedua di mana transmisi terjadi antara ayah dan anak laki-lakinya seperti Maus karya Art Spiegelman, ayah dan anak perempuannya dalam Too Many Men karya Lily Brett, serta ibu dan anak perempuannya dalam Sethe yang ditulis oleh Toni Morisson ataupun karya berbentuk visual dari Karpf, Kellner, dan Wollin yang memposisikan anak perempuan sebagai penerima transmisi, Hirsch menyimpulkan adanya perbedaan yang mendasar di mana dalam kasus ketiga dan keempat, subyektivitas dan intersubyektifitas perempuan menjadi begitu kentara. Hal ini menjadi penggerak yang membuat bayangan masa lalu menjadi lebih dramatis, memungkinkan transmisi trans-generasional dari trauma, dan menunjukkan bahwa impact dan effect yang ditunjukkan jauh lebih kuat dari pada subyeksubyek yang lain. Sehingga transmisi yang terjadi dari ibu kepada anak perempuannya diyakini Hirsch mampu menjadi idiom untuk melukiskan kedekatan generasi pertama dan kedua dalam hal koneksi tubuh yang dikonstruksi oleh ekspektasi kultural. Paradigma posisi ibu dan anak perempuan ini akan menjadi acuan analisis dari proses identifikasi. Namun di sisi lain, hal ini juga mempunyai dampak yang ambivalen karena rentan untuk terjerumus pada apa yang disebut sebagai apropriation atau rememory yaitu bentuk dari over-identification yang memungkinkan untuk mengulang kembali trauma yang dialami oleh generasi pertama dengan melakukan selfwounding. Sedangkan postmemory menghendaki identifikasi yang disebut sebagai heteropathic. Secara garis besar, jenis identifikasi ini memahami posisi generasi kedua (self) sebagai penerima narasi berada di luar jangkauan trauma generasi pertama yang mengalami peristiwa Holocaust (other) sehingga tidak ada retraumatization yang terjadi ketika ia membawa narasi dari saksi Holocaust karena pada kenyataannya, postmemory mengimplikasikan sebuah jarak temporal antara self dan other,...(Hirsch, 2012: 86).

Lebih jauh mengenai posisi identifikasi antara self dan other dengan menekankan pada posisi anak perempuan sebagai apa yang disebut Eva Hoffman (2004: x) sebagai the living connection atau the guardianship of the Holocaust, melalui karya Wolin dan Kellner, Hirsch menggarisbawahi setidaknya dua hal yang membedakan karyakarya tersebut dari karya-karya lain yang garis transmisinya lebih maskulin. Pertama, bentuk identifikasi yang mereka lakukan membatasi self untuk tidak mengabsorpsi pengalaman other, tetapi membawa narasi tersebut untuk diceritakan kepada audiens dengan tetap memberikan jarak temporal dan spasial terhadap masa lalu dan trauma yang tidak bisa terjembatani. Kedua, karya-karya tersebut memberikan ciri partikular feminitas yaitu berupa act of holding-caring, protective, and nurturing,...(Hirsch, 2012: 99).

Gender, dalam konteks postmemory, bagaimanapun ia ditampilkan, akan berfungsi sebagai point of memory. Bahkan ketika gender itu invisible atau absence, maka sebenarnya ia bersifat dialektis. Bagi Hirsch (2012: 245) ...silence, absence, dan emptiness justru selalu present, dan bahkan mungkin menjadi central dalam karya postmemory.

\section{Daftar Pustaka}

Hirsch, Marianne. 2012. The Generation of Postmemory: Writing and Visual Culture after the Holocaust. NY: Colombia Press.

Hoffman, Eva. 2012. After such Knowledge: Memory, History, and the Legacy of the Holocaust. New York: Public Affair.

Stuber, Dorian, 2013. "Marianne Hirsch, The Generation of Postmemory: Writing and Visual Culture after the Holocaust' Bryn Mawr Review of Comparative Literature. Vol 10, No. 2, (Fall): online. 